\title{
Comment on Saber et al. (2019), "Commentary: the chronic inhalation study in rats for assessing lung cancer risk may be better than its reputation"
}

\author{
Kevin E. Driscoll ${ }^{1 *}$ (D, Paul A. Borm ${ }^{2,3}$, Ishrat Chaudhuri', Len Levy ${ }^{5}$, Mei Yong ${ }^{6}$, David Warheit ${ }^{7}$,
} Robert McCunney ${ }^{8}$ and Günter Oberdörster ${ }^{9}$

\begin{abstract}
In their Commentary Saber et al. (Part Fibre Toxicol 16: 44, 2019) argue that chronic inhalation studies in rats can be used for assessing the lung cancer risk of insoluble nanomaterials. The authors make several significant errors in their interpretation and representation of the underlying science. In this Letter to the Editor we discuss these inaccuracies to correct the scientific record. When the science is recounted accurately it does not support Saber et al's statements and conclusions.
\end{abstract}

In the Commentary by Saber et al. [1] the authors argue that "the chronic inhalation study in rats can be used for assessing the lung cancer risk of insoluble nanomaterials". Unfortunately, the Commentary suffers from several major misinterpretations and misrepresentations of the science. When the science is considered accurately it does not support the author's statements and conclusions. Here we discuss a number of these inaccuracies in order to correct the scientific record.

1. A key position taken by Saber et al. [1] is that "inhalation of the insoluble, low toxicity particles induces lung cancer in rats in the absence of impaired clearance". To support their assertion, Saber et al. cite reports by Mauderly et al. [2] and Heinrich et al. [3] which summarize results of chronic inhalation studies in rats. However, a review of these reports reveals the findings directly

\footnotetext{
* Correspondence: kevinedriscoll1@gmail.com

${ }^{1}$ Ernest Mario School of Pharmacy, Rutgers, New Brunswick, NY 07046, USA Full list of author information is available at the end of the article
}

conflict with Saber et al's statements. Specifically, in the Mauderly et al. and Heinrich et al. studies, all particle exposures associated with lung cancer in rats also produced a marked impairment of lung particle clearance (See Mauderly et al. [2] Fig. 24 and Heinrich et al. [3] Table 9). Moreover, the findings of Mauderly et al. and Heinrich et al. are in agreement with other studies showing that development of lung cancer in rats after inhalation of poorly soluble low toxicity particles (PSLT) occurs only under conditions of excessive lung particle overload $[4,5]$. Therefore, the conclusion by Saber et al. [1] that lung cancer occurs in the absence of impaired clearance is not supported by data for PSLT.

2. The authors' statements on species differences in lung particle clearance after PSLT exposure are incorrect. For example, they write in rats, but not in hamsters or mice, impaired clearance has been 
observed at high lung burden" and "particle clearance rates in mice, hamsters and rats depend on the lung burden: lower clearance rates are observed with increasing lung burden, but the impaired clearance is only observed in rats". To support their statements, Saber et al [1] cite a study by Elder et al. [6]; however, the actual results of the Elder et al. study directly contradict the authors' assertions. Specifically, Elder et al. observed a significant, dose-dependent impairment of lung particle clearance in rats, mice and hamsters exposed for 13 weeks by inhalation to carbon black (CB) (see Elder et al. [6] Table 4) and concluded all three species showed lung particle overload under similar exposure scenarios. The Elder et al. findings concur with other studies, including Muhle et al. [7] who demonstrated that rats and hamsters both exhibit impaired lung particle clearance at high lung burdens of PSLT.

3. To support their contention that rat lung cancer after PSLT inhalation reflect a human hazard, the authors discuss coal miner epidemiology as an example of "occupational exposure to carbon dust". The basis of this argument is seriously flawed as coal miners are exposed to a complex mixture of substances which can include soluble materials as well as crystalline silica, a known human carcinogen [8]. As such, coal miner exposure is not a surrogate for exposure to a PSLT and is much more than simply exposure to carbon dust. Having not appreciated the compositional differences between mixed dust coal miner exposure and exposure to a PSLT, the authors selectively discuss two coal miner epidemiology studies that reported an apparent increase in lung cancer risk $[9,10]$ among numerous studies that have reported no excess lung cancer risk [11].

4. Saber et al. [1] argue a comparison of lung cancer risk estimates for diesel exhaust derived from inhalation studies in rats and occupational epidemiology indicates "chronic inhalation studies in rats do not overestimate carcinogenic risks". As with the coal miner exposures, diesel exhaust exposure involves a complex mixture of carbonaceous particles and adsorbed organics including carcinogenic nitro and aromatic compounds [12]. As such, the diesel exhaust epidemiology is not relevant to PSLT exposures.
Considering the epidemiology for actual PSLTs, we note that titanium dioxide $\left(\mathrm{TiO}_{2}\right)$ and $\mathrm{CB}$ both have an extensive high-quality data base indicating no exposure-response relationship to lung cancer risk $[13,14]$. Le at al [13] reported a meta-analysis of greater than 25,000 $\mathrm{TiO}_{2}$ production workers and showed no elevated risks for lung cancer mortality or non-malignant respiratory disease. Also, a metaregression of $\mathrm{CB}$ mortality studies found no exposure-response relationship for $\mathrm{CB}$ and lung cancer in upwards of $9000 \mathrm{CB}$ production workers [14].

In summary, understanding the relevance of rodent toxicology studies to human risk assessment is critically important. Unfortunately, in their Commentary, Saber et al. [1] make several significant errors in their interpretation and representation of key studies which, when accurately considered, do not support the author's statements and conclusions on relationships between lung clearance and rat lung cancer; species differences; and the predictiveness of rat lung cancer for nanosized PSLT. Germane to this discussion are the outcomes of a recent workshop on inhaled PSLT where a panel of 15 experts on PSLT toxicology and regulatory matters reached consensus that "rat lung tumors occurring with PSLT only under lung particle overload are not relevant to humans under non-overload exposure conditions" [15].

Authors' contributions

The manuscript was prepared collaboratively and has been reviewed and approved by all authors.

Funding

No funding was received for writing this Letter to the Editor.

Availability of data and materials

Not applicable.

Ethics approval and consent to participate

Not applicable.

Consent for publication

Not applicable.

\section{Competing interests}

The authors declare that they have no known competing financial interests or personal relationships that could have appeared to influence the work reported in this paper. IC, LL, BM and MY are members of the Scientific Advisory Group to the International Carbon Black Association, which is a scientific, non-profit corporation, the purpose of which is to encourage and develop international communication, cooperation, and research concerning carbon black environmental, health, and safety matters and related regulatory matters. $\mathrm{IC}$ is an employee of a carbon black manufacturing company. $\mathrm{PB}$ is consultant to Imerys.

\section{Author details}

${ }^{1}$ Ernest Mario School of Pharmacy, Rutgers, New Brunswick, NY 07046, USA. ${ }^{2}$ Nanoconsult, Meerssen, Netherlands. ${ }^{3}$ Düsseldorf University, Düsseldorf, Germany. ${ }^{4}$ Cabot Corporation, Billerica, MA, USA. ${ }^{5}$ Cranfield University, Cranfield, UK. ${ }^{6} \mathrm{MY}$ EpiConsulting, Düsseldorf, Germany. ${ }^{7}$ Warheit Scientific LLC, Wilmington, Delaware, USA. ${ }^{8}$ Pulmonary Division, Brigham and Women's 
Hospital, Harvard Medical School, Cambridge, MA, USA. ${ }^{9}$ School of Medicine and Dentistry, University of Rochester, Rochester, NY, USA.

Received: 30 June 2020 Accepted: 8 July 2020

Published online: 16 July 2020

\section{References}

1. Saber AT, Poulsen SS, Hadrup N, Jacobsen NR, Vogel U. Commentary: the chronic inhalation study in rats for assessing lung cancer risk may be better than its reputation. Part Fibre Toxicol. 2019;16:44.

2. Mauderly JL, Snipes MB, Barr EB, Belinsky SA, Bond JA, Brooks AL, et al. Pulmonary toxicity of inhaled diesel exhaust and carbon black in chronically exposed rats. Part I: Neoplastic and nonneoplastic lung lesions. Res Rep Health Eff Inst. 1994;68(Pt 1):1-75.

3. Heinrich $U$, Fuhst $R$, Rittinghausen $S$, Creutzenberg O, Bellmann B, Koch W, et al. Chronic inhalation exposure of Wistar rats and two different strains of mice to diesel engine exhaust, carbon black, and titanium dioxide. Inhal Toxicol. 1995;7(4):533-56

4. Bevan RJ, Kreiling R, Levy LS, Warheit DB. Toxicity testing of poorly soluble particles, lung overload and lung cancer. Regul Tox Pharm. 2018;100:80-91.

5. Oberdörster G. Lung particle overload: implications for occupational exposures to particles. Reg Toxicol Pharm. 1995;21:123-35.

6. Elder A, Gelein R, Finkelstein JN, Driscoll KE, Harkema J, Oberdörster G. Effects of subchronically inhaled carbon black in three species. I. Retention kinetics, lung inflammation, and histopathology. Toxicol Sci. 2005:88(2):614-29.

7. Muhle H, Creutzenberg O, Bellmann B, Heinrich U, Mermelstein R. Dust overloading of lungs: investigations of various materials, species differences, and irreversibility of effects. JAerosol Med. 1990;3(s1):S-111 S-28.

8. McCunney RJ, Morfeld P, Payne S. What component of coal causes coal workers' pneumoconiosis? JOccup Environ Med. 2009:51(4):462-71.

9. Graber JM, Stayner LT, Cohen RA, Conroy LM, Attfield MD. Respiratory disease mortality among US coal miners; results after 37 years of follow-up. Occup Enviro Med. 2014;71(1):30-9.

10. Taeger D, Pesch B, Kendzia B, Behrens T, Jöckel K-H, Dahmann D, et al. Lung cancer among coal miners, ore miners and quarrymen: smoking-adjusted risk estimates from the synergy pooled analysis of case-control studies. Scand J Work Environ Health. 2015;41(5):467-77.

11. Morfeld P, Bruch J, Levy L, Ngiewih Y, Chaudhuri I, Muranko HJ, et al. Translational toxicology in setting occupational exposure limits for dusts and hazard classification - a critical evaluation of a recent approach to translate dust overload findings from rats to humans. Part Fibre Toxicol. 2015;12:3.

12. IARC. Monographs on the evaluation of carcinogenic risks to humans. Diese and gasoline engine exhausts and some nitroarenes, vol. 105. Lyon: World Health Organization; 2014.

13. Le HQ, Tomenson JA, Warheit DB, Fryzek JP, Golden AP, Ellis ED. A review and meta-analysis of occupational titanium dioxide exposure and lung Cancer mortality. J Occup Environ Med. 2018;60(7):e356-e67.

14. Yong M, Anderle L, Levy L, McCunney RJ. Carbon black and lung Cancer mortality-a meta-regression analysis based on three occupational cohort studies. J Occup Environ Med. 2019;61(11):949.

15. Driscoll KE, Borm PJA. Expert workshop on the hazards and risks of poorly soluble low toxicity particles. Inhal Toxicol. 2020; 32(2):53-62.

\section{Publisher's Note}

Springer Nature remains neutral with regard to jurisdictional claims in published maps and institutional affiliations.

Ready to submit your research? Choose BMC and benefit from:

- fast, convenient online submission

- thorough peer review by experienced researchers in your field

- rapid publication on acceptance

- support for research data, including large and complex data types

- gold Open Access which fosters wider collaboration and increased citations

- maximum visibility for your research: over $100 \mathrm{M}$ website views per year

At $\mathrm{BMC}$, research is always in progress.

Learn more biomedcentral.com/submissions 